\title{
Did the First Iron Blacksmiths Learn to Carburize Iron? Part I: Can Iron be Carburized in a Charcoal-Fired Furnace?
}

\author{
J.D. VERHOEVEN, ${ }^{1,4}$ A.H. PENDRAY, ${ }^{2}$ and W.E. DAUKSCH ${ }^{3}$ \\ 1.-Iowa State University, Ames, IA, USA. 2.-Master ABS Bladesmith, Williston, FL, USA. \\ 3.-Nucor Corp, Charlotte, NC, USA. 4.—e-mail: jver@iastate.edu
}

There is debate in the literature on whether or not iron can be carburized by simply inserting an iron bar into a charcoal fire. Experiments are presented here in which wrought iron bars have been held in a cylindrical enclosure filled with burning charcoal produced by air flowing up from tuyeres at the bottom with the bottom end of the bars held in the $900^{\circ} \mathrm{C}-1050^{\circ} \mathrm{C}$ range for $30 \mathrm{~min}$. The bars carburized to a remarkable extent. Martensite case depths on a water-quenched bar were measured ranging from $0.75 \mathrm{~mm}$ at the hot bottom end and dropping to $0.02 \mathrm{~mm}$ at a distance of $295 \mathrm{~mm}$ (11.6 inches) up the bar. The surface of the bar was file hard over this length with measured surface hardnesses in the 60-65 Rc range.

\section{INTRODUCTION}

Many authors ${ }^{1-4}$ have assumed that the earliest ancient iron smiths from the 1200 to $900 \mathrm{BC}$ time period were able to convert the first iron made by man (called bloomery iron and generally containing less than $0.1 \% \mathrm{C}$ ) to steel by carburizing in charcoal fires. However, Rehder ${ }^{5}$ in a 1989 paper and later in his book ${ }^{6}$ has argued on theoretical grounds that this idea cannot be supported. Wagner ${ }^{4}$ has taken issue with Rehder's claim, again largely on theoretical grounds. It is well established that iron can be carburized when heated in charcoal contained in closed containers. This was done on industrial scales in the production of blister steel in England from 1600 to $1951,{ }^{1}$ and is still done on occasion in pack-carburizing operations. ${ }^{7}$ The difficulty with predicting if an open charcoal fire will carburize iron can be understood from the following analysis.

When charcoal is burned in air, a mixture of $\mathrm{CO}$ and $\mathrm{CO}_{2}$ is generated. When the $\mathrm{CO}$ comes into contact with the iron, carbon atoms are able to dissolve into the iron according to the following chemical reaction:

$$
2 \mathrm{CO} \rightarrow \mathrm{CO}_{2}+[\mathrm{C}],
$$

where the bracket around the $\mathrm{C}$ means the carbon is dissolved in the iron matrix. The equilibrium constant for this reaction can be written as,

W.E. Dauksch—retired from Nucor Corp.

$$
K_{1}=\gamma\left[C_{\mathrm{g}}\right] \mathrm{P}_{\mathrm{CO}_{2}} / \mathrm{P}_{\mathrm{CO}}^{2},
$$

where $\gamma$ is the activity coefficient of carbon in pure iron, $\mathrm{P}_{\mathrm{CO} 2}$ is the partial pressure of carbon dioxide in the gas, $\mathrm{P}_{\mathrm{CO}}$ is the partial pressure of carbon monoxide in the gas, and $\left[C_{g}\right]$ is the weight percent carbon dissolved in the iron. It is common to call this latter term the carbon potential of the gas. It tells you the $\% \mathrm{C}$ that will dissolve into the iron right at the iron surface contacting the gas under equilibrium conditions. The values of both $K_{1}$ and $\gamma$ have been measured as a function of temperature, ${ }^{8}$ and one can use Eq. 2 along with the stoichiometry of the air/carbon burning reaction to calculate $R$, the ratio of the $\mathrm{CO} / \mathrm{CO}_{2}$ pressures, versus carbon potential.

Figure 1 presents the predicted values of $\mathrm{R}$ vs $C_{\mathrm{g}}$ for the temperatures at $740^{\circ} \mathrm{C}, 820^{\circ} \mathrm{C}, 900^{\circ} \mathrm{C}$ and $1000^{\circ} \mathrm{C}$. The data all extend up to the saturation values of $\mathrm{C}$ in austenite at the respective temperatures. For $740^{\circ} \mathrm{C}$ and $820^{\circ} \mathrm{C}$, they extend down to the minimum solubility of $\mathrm{C}$ in austenite. For useful applications, it is generally assumed that one needs temperatures in the $900^{\circ} \mathrm{C}-1000^{\circ} \mathrm{C}$ range to achieve sufficient diffusion rates to produce adequate case depths of increased carbon at the surface of iron bars. It can be seen from Fig. 1 that $R$ values of the order of 50 or more are predicted to be needed to produce significant values of $C_{\mathrm{g}}$ at the surface. So the problem of predicting from theory whether or not one can achieve significant carburization in a 
charcoal fire stems from the difficulty of predicting the value of $R$ versus temperature in charcoal fires. Several attempts were made in the early twentieth century $^{9-12}$ to evaluate the levels of the gas content, $\mathrm{O}_{2}$, $\mathrm{CO}$ and $\mathrm{CO}_{2}$ in charcoal beds with air blowing up or down a stack of charcoal. In these studies, the burning charcoal was contained in heat-resistant cylindrical chambers with air blowing through the charcoal either by natural convection or forced flow and exiting into the open atmosphere. This arrangement will be referred to here as a charcoal-fired furnace and is the arrangement used in this study. In the work of Hiles and Mott ${ }^{9}$ on wood charcoal, the maximum value of $R$ was only 32 , and it was largely on the basis of the data of Hiles and Mott that Rehder made his conclusion that it was unlikely that the assumption that iron can be easily carburized by insertion into a charcoal fire was correct (pp 137-138 and $\mathrm{p} 195$ of Rehder ${ }^{6}$ ). In this study, a few experiments have been carried out to settle this question. These experiments utilized a charcoal fire arrangement modeled after that probably used by some ancient smiths who first made iron in bloomery furnaces.

Bloomery iron was made by our blacksmith ancestors by blowing air up through a cylindrical stack of alternating layers of charcoal and iron ore. ${ }^{3}$ The temperatures achieved were not adequate to melt the reduced iron, and particles of solid iron fell down through a molten slag and sintered together into what is called a bloom. These blooms contained as much as $50 \%$ by volume of slag inclusions and void porosity. This bloom iron had to be re-heated and forged to both remove the slag, which would become viscous at the forging temperatures, and to form useful shapes. The resulting iron would contain slag stringers in an iron matrix and have virtually the same microstructure as that of modern wrought iron.

\section{EXPERIMENTAL DESIGN}

Because the early smiths had to heat the bloomery iron in order to forge it into useful shapes, it seems quite reasonable that at least some of them used the same bloomery furnaces to heat the iron to forging temperatures. Therefore, these experiments on evaluating carburization of iron were done in hot charcoal contained in a cylindrical furnace that has been used to successfully produce bloomery iron from iron ore. Figure 2 presents a schematic view of the arrangement of the present experiments. An air blower was used to supply air to the two tuyeres at an equal and adjustable rate. The first experiment ran 2 bars and began by filling the furnace with crushed charcoal to a level of 3 inches $(76 \mathrm{~mm})$ below the top. Four thermocouples extended vertically into the chamber, one from below and three from above as shown in Fig. 2. They consisted of ceramic-insulated type $\mathrm{K}$ wire contained in 3/16-in-diameter $(4.8 \mathrm{~mm})$ Inconel sheath. The experiment began by adding propane to

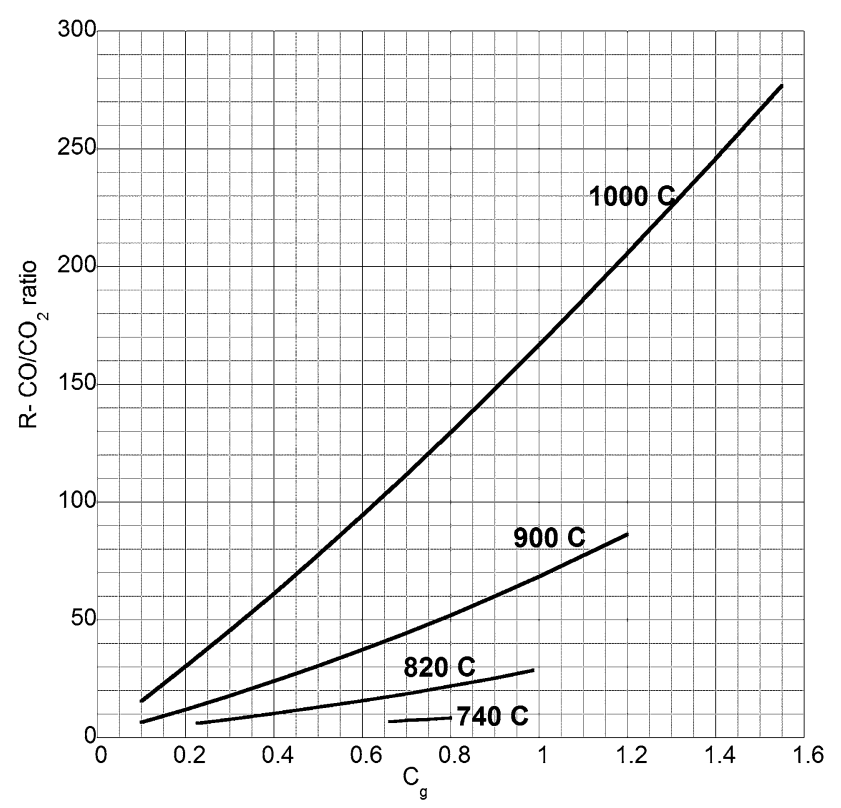

Fig. 1. The $\mathrm{CO} / \mathrm{CO}_{2}$ ratio needed to produce the carbon potential $C_{\mathrm{g}}$ (wt\%).

the air for a short time to ignite the charcoal and then turning off the propane and controlling the air flow to heat the charcoal bed. The temperature was cycled between $1050^{\circ} \mathrm{C}$ and $950^{\circ} \mathrm{C}$ on the bottom thermocouple, tc 1 , by turning the air on and off with charcoal being periodically added to the top. After 80 min, which included 3 cycles, two wrought iron plates, marked A and B, were inserted into the charcoal such that the bottom of the plates were located at the tip of thermocouple 2. A 15-mmdiameter rod was welded to the upper end of each plate. It extended up to the holder plate to position and hold the wrought iron plates stationary. The plates were positioned with the set of 3 thermocouples sandwiched between them. Plate A measured $44 \mathrm{~mm}$ wide by $3.4 \mathrm{~mm}$ thick and B was $48 \mathrm{~mm}$ by $4.5 \mathrm{~mm}$ and each was $340 \mathrm{~mm}$ (13.4 inches) in length. The plates were coded bar A2-13 and bar B2-13 for the $\mathrm{A}$ and $\mathrm{B}$ irons, respectively.

The charcoal used in the experiments was $100 \%$ all natural hardwood charcoal which came in individual sizes up to $80-100 \mathrm{~mm}$. This charcoal was crushed into smaller sizes with a mallet and the final size range used in the experiments was the resultant mixture ranging from very fine up to the largest sizes whose long dimension ranged up to around $25 \mathrm{~mm}$.

The two bars were made of wrought iron because wrought iron is an excellent match of the old bloomery iron. Just as with bloomery iron, wrought iron is essentially a nearly pure iron containing copious stringers of slag inclusions. The plates were made from two different large pieces known to be wrought iron by forging followed by rolling. Chemical analyses of the plates were determined by emission spectroscopy and are presented in Table I. 
After the bars were inserted into the hot charcoal bed, the temperatures of the thermocouples all dropped significantly. Figure 3 shows the recorded temperatures beginning at the time where the temperatures had just bottomed out. The first experiment was terminated by removing bar A2-13 and quenching it in water after a time period of roughly $30 \mathrm{~min}$ after the temperature at the bottom of the plate, thermocouple 2 , had exceeded around $900^{\circ} \mathrm{C}$. The tip of thermocouple 3 was positioned $89 \mathrm{~mm}$ (3.5 inches) above the bottom of the plate and that of thermocouple 4 was $165 \mathrm{~mm}$ (6.5 inches) above. After quenching bar A2-13, the temperature was cycled between $950^{\circ} \mathrm{C}$ and $1050^{\circ} \mathrm{C}$ on thermocouple 2 for another 30 min after which bar B2-13 was quenched in water.

\section{Evaluation of Extent of Carburization}

The as-quenched bars were analyzed by sectioning them at 25-mm (1-inch) intervals up from their bottom ends. Two longitudinal strips were then cut
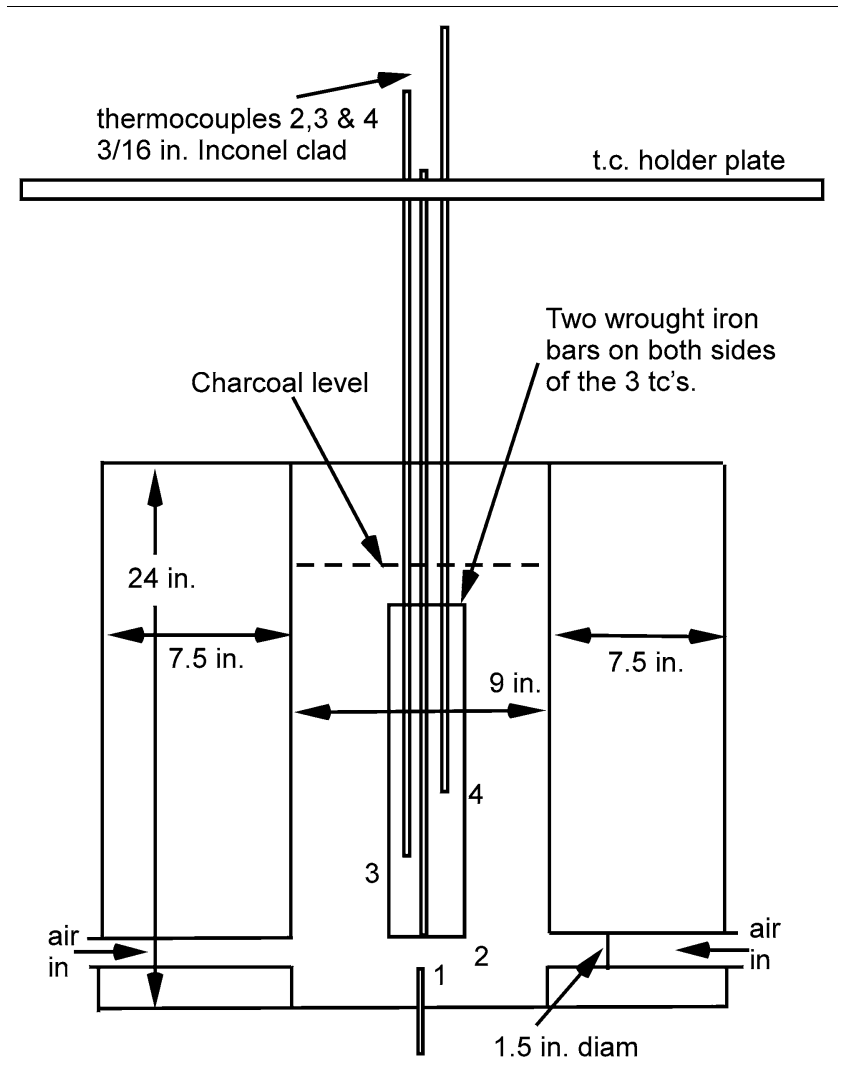

Fig. 2. Schematic diagram of experimental apparatus. from each section and one was mounted and polished on the carburized face and the other on the longitudinal section. The mounted samples were polished through 1- $\mu \mathrm{m}$ diamonds using standard metallographic techniques. The face sections were polished very lightly so as to remove the least amount of carburized case as possible. The surface hardness was then measured at intervals along the strips using a Wilson microhardness machine employing a 2-kg load and a diamond pyramid indenter. These measurements were taken after the machine was calibrated with a standard sample whose DPH (diamond pyramid hardness) had also been determined with a 2 -kg load. The longitudinal transverse strips were etched in nital which produces a well-defined surface case as the martensite case etches dark and the ferrite interior etches white. Consequently, the case depth could be evaluated fairly accurately. The case depths were measured at intervals along the strips using a calibrated filar eyepiece on an optical microscope with increasing objective lens magnification as the case depths became smaller.

Figures 4 and 5 present the results for the runs with bars A2-13 and B2-13, where the DPH hardness values have been converted to their equivalent $\mathrm{Rc}$ values. There are several interesting results. One of the most interesting outcomes came from a

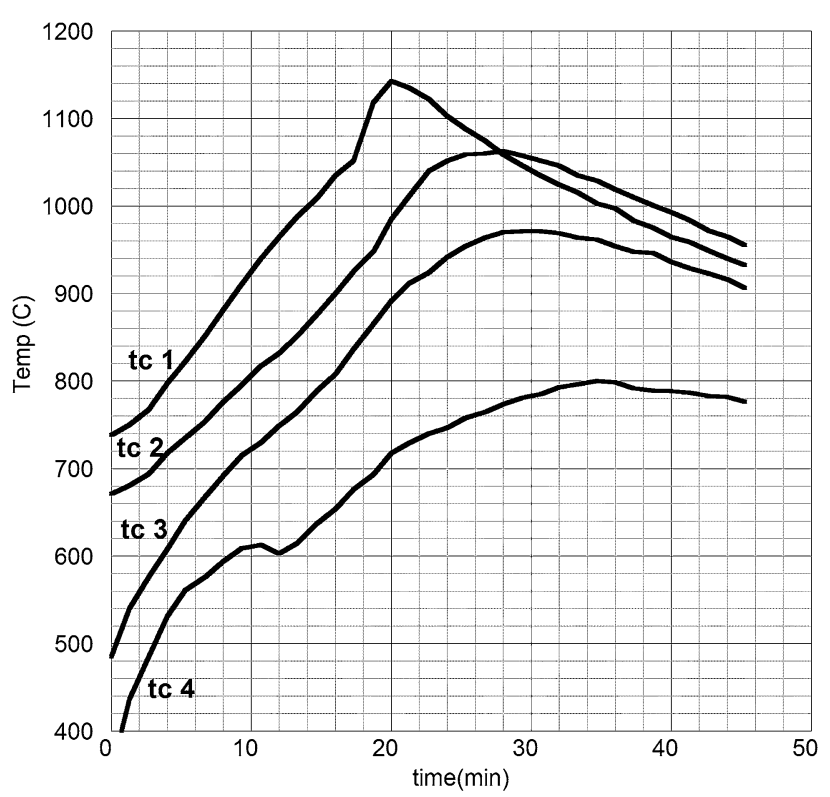

Fig. 3. Temperature profiles for experiment 1.

Table I. Emission spectrograph analysis of the wrought iron plates

\begin{tabular}{|c|c|c|c|c|c|c|c|c|c|c|c|}
\hline Plate & $\mathbf{C}$ & Mn & $\mathbf{S i}$ & $\mathbf{S}$ & $\mathbf{P}$ & $\mathbf{C u}$ & $\mathbf{C r}$ & $\mathbf{N i}$ & Mo & $\mathbf{V}$ & Al \\
\hline $\mathrm{A}$ & 0.001 & 0.097 & 0.144 & 0.036 & 0.120 & 0.315 & 0.038 & 0.017 & 0.005 & 0.004 & 0.030 \\
\hline B & 0.063 & 0.086 & 0.120 & 0.007 & 0.083 & 0.056 & 0.021 & 0.014 & 0.001 & 0.001 & 0.012 \\
\hline
\end{tabular}






Fig. 4. A2-13 case depth and Rc values versus $Z$.

simple surface file hardness test. The samples were held firmly in a vice and a small file, measured to have a hardness or Rc $=55$, was scraped along the edge of the bars. At the top of the bar, the file would easily remove the iron along the edge but at some point toward the bottom it could not begin to remove metal and in fact after a couple of efforts it showed distinct signs of wear on its surface. This technique of qualitatively evaluating steel surface hardness is an old well-established test discussed by Kehl. ${ }^{13}$ In this case, it correlated very well with the locations in both bars coming down from the top of the bars where the measured case depth had risen from zero to only $0.015-0.02 \mathrm{~mm}$. In both bars, it can be seen that the case depth continues to rise to substantial values as the bottom of the bars is approached. The position of the thermocouples is indicated in Fig. 4.

Experiments have shown in $\mathrm{Kehl}^{13}$ that there is a minimum thickness that must be maintained in the diamond pyramid hardness test, often called the Tukon test, for accurate results. The recommended minimum thickness is 1.5 times the length of the diagonal of the indent. For the hardnesses in the $\mathrm{Rc}=60-66$ range found here with a $2-\mathrm{kg}$ load, that works out to be a thickness of $0.105 \mathrm{~mm}$. Hence, for case depths thinner than this value, we expect the surface Rc values to begin to fall off as the indenter will begin to penetrate through the martensite case into the soft ferrite core. This limiting Tukon case depth is shown in Figs. 4 and 5, and in both cases it is seen that the Rc values do fall off just beyond this case depth. As will be explained in the "Discussion" section, it is likely that the Rc $=60-66$ hardness is

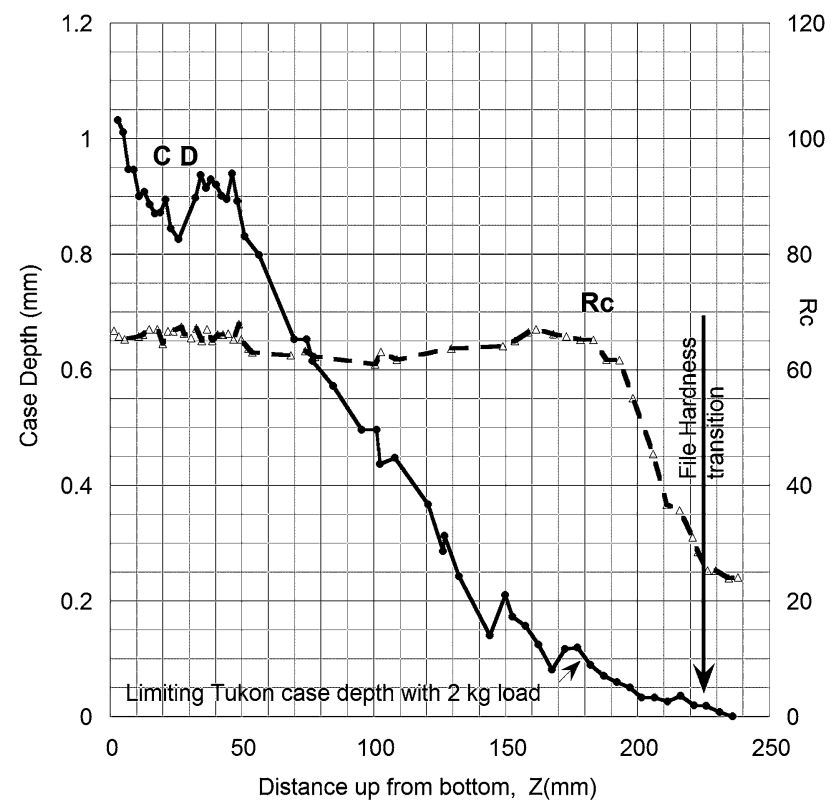

Fig. 5. B2-13 case depths and Rc values versus $Z$.

maintained at this value right out to the edge of the thinnest case in agreement with the file hardness transition results.

It was expected that bar B2-13 would show significantly more carburization because it was carburized for an additional $30 \mathrm{~min}$, but this was not found to be the case. The data of Fig. 4 show that the $30-$ min run of A2-13 has produced a file hardness case significantly farther up the bar than the $60-\mathrm{min}$ run of B2-13, $295 \mathrm{~mm}$ versus $225 \mathrm{~mm}$. From about $100 \mathrm{~mm}$ and up, B2-13 has a smaller case than the A2-13 bar. But the case depths in both bars in these regions must have been the same at 30 min when A2-13 was water-quenched. This result shows that, during the additional $30 \mathrm{~min}$ that B2-13 was held prior to quenching, the bar must have decarburized. The thicker case depth in the bottom $70 \mathrm{~mm}$ of the B2-13 bar shows that the case must have initially carburized to a deeper level than A2-13 but is consistent with decarburization in the later stages of the additional 30-min treatment. The small rise in case depth from $20 \mathrm{~mm}$ to $50 \mathrm{~mm}$ in B2-13 is consistent with a stronger decarburization right near the bottom of the bar. One expects ash to accumulate in the bottom of the furnace as time proceeds. This inert material would allow the oxygen entering from the furnace bottom to extend further up the furnace before converting to $\mathrm{CO}$, and thereby lowering the $\mathrm{CO} / \mathrm{CO}_{2}$ ratio and the corresponding carbon potential giving rise to decarburization as the carbon potential falls from previous values.

An additional experiment was carried out that allowed an evaluation of the effect of ash content accumulated in the bottom of the furnace during operation upon the extent of carburization. The 
furnace was first filled with fresh charcoal and heated to the same temperature range as shown in Fig. 3 but then allowed to cool overnight. Fresh charcoal was then added to the top of the furnace in small increments and the fire was established from the top down until the thermocouples were in the desired temperature range. A wrought iron bar of the A iron of the same shape and size as A2-13 but coded A2-15 was inserted into the hot charcoal in an identical manner as done for A2-13 and held at temperature for 10 min longer than A2-13. The case depths of A2-15 were significantly smaller than A213 dropping from $0.75 \mathrm{~mm}$ to $0.5 \mathrm{~mm}$ at the surface and the file hardness length dropping from $295 \mathrm{~mm}$ to $225 \mathrm{~mm}$. The significantly larger ash accumulation in the lower section of the furnace in A2-15 seems most likely to be the reason for these differences.

\section{DISCUSSION}

The present experiments were done in part to evaluate the likelihood that ancient smiths might have learned to carburize bloomery iron in order to produce cutting and scraping tools having hardnesses superior to the hardest bronzes, $\mathrm{DPH}=270$, $\mathrm{Rc}=26$. The experiments show that file-hard thin cases can be readily produced at the lowest temperatures capable of carburizing iron, just above the $A_{1}$ temperature at which austenite will form when iron absorbs carbon. In the temperature range from $727^{\circ} \mathrm{C}$ to $912^{\circ} \mathrm{C}$, hypoeutectoid iron carbon alloys exist in a two-phase region located between the $\mathrm{A}_{1}$ and $\mathrm{A}_{3}$ temperatures. This temperature region is often referred to as the intercritical region where low-carbon dual phase and TRIP steels are annealed. ${ }^{14}$ For the case of diffusion in binary alloys, regions of two-phase mixtures will not form. ${ }^{15}$ Consequently, carburization of iron at temperatures in the intercritical range will produce a planar austenite-ferrite interface advancing from the surface into the ferrite core. Figure 6 illustrates the very sharp interface that forms at the inner austenite-ferrite boundary for diffusion at temperatures in the intercritical range. The micrograph was taken on bar A2-13 at the location of $Z=254 \mathrm{~mm}$ with an estimated temperature of $755^{\circ} \mathrm{C}$. It also illustrates an interesting effect of interface diffusion at this low temperature. The arrows show locations where carbon has diffused along ferrite-ferrite grain boundaries ahead of the advancing planar austenite-ferrite boundary, while the nearby slag inclusions are preferentially surrounded by a martensite layer, apparently due to the rapid diffusion of carbon along ferrite-slag interfaces, shown most clearly at the elongated slag inclusions at arrow 4.

Adda and Philibert ${ }^{16}$ have presented the solution of the diffusion equations at temperatures in the intercritical region for the case where the surface composition jumps up instantaneously at time zero

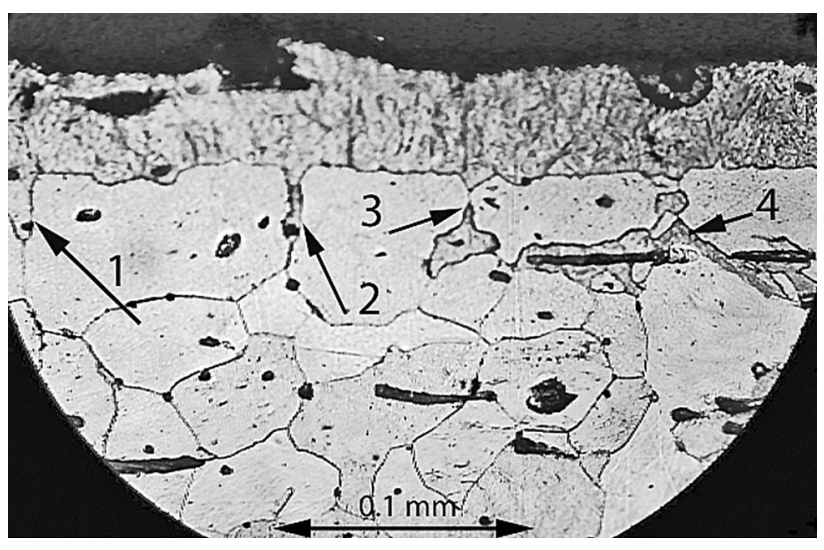

Fig. 6. Micrograph bar A2-13 at location $Z=254 \mathrm{~mm}\left(\mathrm{~T} \sim 755^{\circ} \mathrm{C}\right)$.

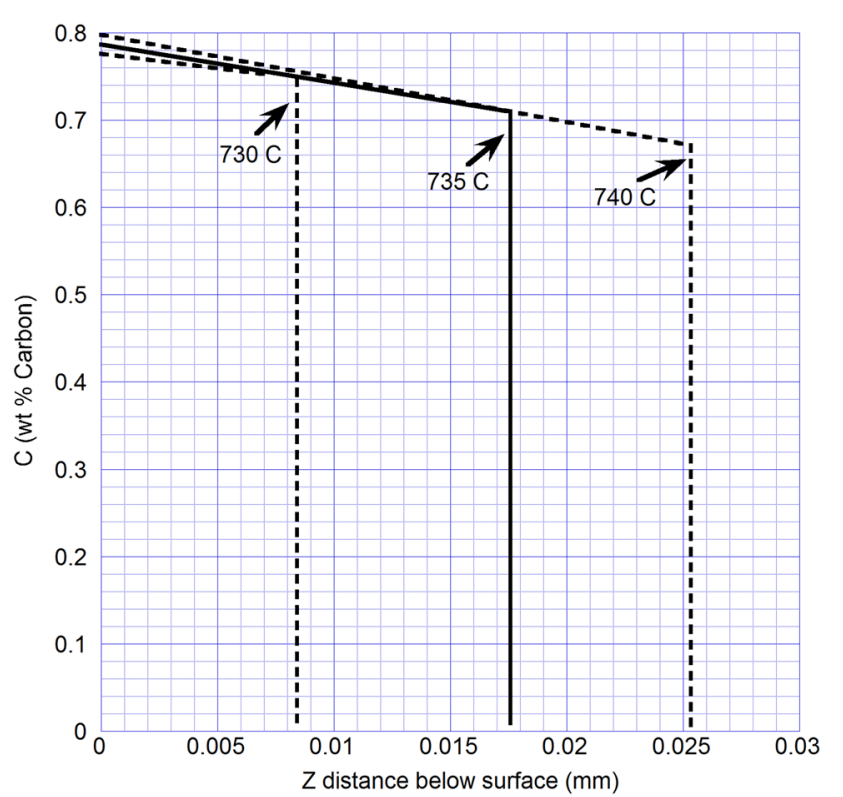

Fig. 7. Predicted composition profile from Adda-Philibert solution at $730^{\circ} \mathrm{C}, 735^{\circ} \mathrm{C}, 740^{\circ} \mathrm{C}$ for $30 \mathrm{~min}$.

to a constant value. This assumption becomes better at longer diffusion times and Fig. 7 shows the results of the solution for the 30-min experiment of A2-13. The solution is a function of the composition at the surface which was taken as the saturation value of $A_{\mathrm{cm}}$, as well as the $A_{3}$ concentration, the ferrite saturation concentration and the carbon diffusion coefficient in ferrite, all of which were taken from the equations presented in Ref. 17 The average value of the diffusion coefficient in austenite is also required and was taken from Ref. 18 The solution shows the carbon composition in the surface austenite layer drops linearly from the $A_{\mathrm{cm}}$ value to the $A_{3}$ value at the advancing planar interface, and it predicts a resultant martensitic case depth of $0.015-0.02 \mathrm{~mm}$ at temperatures between $735^{\circ} \mathrm{C}$ and $740^{\circ} \mathrm{C}$. This result agrees well with the results of the present experiments which produced case depths in this range at the lowest 
temperature location up the bar displaying file hardness. Notice also that the results show that the martensite cases formed on these thin cases at the lowest temperatures would be very hard, as the Rc value of fresh martensite with $\% \mathrm{C}$ in the $0.7-$ $0.8 \%$ range is $64-65(800-830 \mathrm{DPH}){ }^{14}$ As expected, the inner martensite case boundary was found to be quite sharp at the lower temperature regions of the bars and diffuse at the hotter regions above the maximum intercritical temperature of $912^{\circ} \mathrm{C}$. Notice also from Fig. 1, that at $740^{\circ} \mathrm{C}$ the value of the $\mathrm{CO} / \mathrm{CO}_{2}$ ratio, $R$, is significantly smaller than at higher temperatures. Hence, even if the $R$ values produced in charcoal fires do not exceed 32 , as found in Ref. 9, carburizing iron bars in them should produce thin martensite surface layers. Even if they are very thin, the surfaces so produced will be file hard.

\section{CONCLUSION}

1. As explained above, a charcoal-fired furnace is defined here as burning charcoal contained in heat-resistant cylindrical chamber with air blowing through the charcoal either by natural convection or forced flow and exiting into the open atmosphere. A charcoal fire is defined as a pile of charcoal with no confining walls and air feeding the fire either by natural convection or forced flow into the open atmosphere. Rehner's conclusion that iron cannot be carburized in a charcoal fire is based on the experimental results of Hiles and $\mathrm{Mott}^{9}$ in which a charcoalfired furnace arrangement was used in experiments that measured $\mathrm{CO}$ and $\mathrm{CO}_{2}$ levels. Consequently, his conclusion applies to both a charcoal fire and a charcoal-fired furnace. His conclusion may well be correct for a charcoal fire, particularly if the pile of charcoal is shallow. However, these experiments show that his conclusion is not correct for a charcoal-fired furnace.

2. Blacksmiths often use charcoal fires to heat iron for forging. These charcoal fires can have many geometrical configurations but most often utilize air blowing into the charcoal from the bottom. However, in the case of Japanese sword making, ${ }^{19}$ the air comes in from the side. These experimental results show that, as long as the pile of charcoal is large enough in both lateral and vertical extent, and as long as ash accumu- lation in the region where the air enters the charcoal stack is avoided, significant carburization of the iron can be produced at sample temperatures of $900^{\circ} \mathrm{C}-1050^{\circ} \mathrm{C}$. It is interesting to point out that Japanese sword makers have been using the side entry method of controlling the carbon content of their small pieces of tamahagane bloomery irons for centuries, being able to carburize or decarburize them, see Figs. 42 and 43 of Ref. 19. This side entry technique of introducing the air would avoid ash accumulation into the area where the air enters the stack of charcoal.

\section{ACKNOWLEDGEMENTS}

The authors would like to acknowledge Nucor Steel Company for carrying out the chemical analysis of the irons used here and Iowa State University for the use of metallography equipment. We also thank Jeremy Jennings for help with initial experiments and equipment modification.

\section{REFERENCES}

1. K.C. Barraclough, Steelmaking Before Bessemer, vol. 1 (London: The Metals Society, 1984).

2. T.S. Wheeler and R. Maddin, The Coming of the Age of Iron, ed. T.A. Wertime and J.D. Muhly (New Haven: Yale University Press, 1980), p. 99.

3. W. Rostoker and B. Bronson, Pre-Industrial Iron, Its Technology and Ethnology (Philadelphia: Archeomaterials Monograph No. 1, 1990).

4. D.R. Wagner, Archeomaterials 4, 111 (1990).

5. J.E. Rehder, Archeomaterials 3, 27 (1989).

6. J.E. Rehder, The Mastery and Uses of Fire in Antiquity (Montreal: McGill-Queen's University Press, 2000).

7. H. Chandler, eds., Heat Treater's Guide, Practices and Procedures for Irons and Steels, 2nd ed. (Metals Park: ASM International, 1995), p. 50.

8. F.J. Harvey, Met. Trans. A 9A, 1507 (1978).

9. J. Hiles and R.A. Mott, Fuels Sci. Pract. 23, 154 (1944).

10. N. Karzhavina, Fuels Sci. Pract. 19, 220 (1940).

11. M.K. Grodzovsky and Z.F. Choukhanoff, Fuels Sci. Pract. 15, 321 (1936).

12. T.F.E. Ehead and R.V. Wheeler, J. Chem. Soc. Trans. 103, 461 (1913).

13. G.L. Kehl, Metallographic Laboratory Practice (New York: McGraw-Hill, 1949).

14. G. Krauss, Steels: Processing, Structure and Performance, 2nd ed. (Materials Park: ASM International, 2015).

15. J.D. Verhoeven, Fundamentals of Physical Metallurgy (New York: Wiley, 1975), p. 146.

16. Y. Adda and J. Philibert, La Diffuion Dans Les Solides, Tome 1 (Paris: Presses Universitaires De, 1966), p. 182.

17. J.D. Verhoeven, Mater. Charact. 25, 221 (1990).

18. G.G. Tibbetts, J. Appl. Phys. 51, 4813 (1980).

19. L. Kapp, H. Kapp, and Y. Yosihara, The Craft of the Japanese Sword (New York: Kodansha, 2012). 